\title{
Reliability Modelling of PEM Fuel Cells with Hybrid Petri Nets
}

\author{
A. Vasilyev \& J. D. Andrews \\ The University of Nottingham, Nottingham, UK \\ L. M. Jackson \& S. Dunnett \\ Loughborough University, Loughborough, UK
}

\begin{abstract}
In this paper, a novel model for dynamic reliability analysis of a PEM fuel cell system is developed using Modelica language in order to account for multi-state dynamics and aging. The modelling approach constitutes the combination of physical and stochastic sub-models with shared variables. The physical model consist of deterministic calculations of the system state described by variables such as temperature, pressure, mass flow rates and voltage output. Additionally, estimated component degradation rates are also taken into account.

The non-deterministic model, on the other hand, is implemented with stochastic Petri nets which represent different events that can occur at random times during fuel cell lifetime. A case study of effects of a cooling system on fuel cell performance was investigated. Monte Carlo simulations of the process resulted in a distribution of system parameters, thus providing an estimate of best and worst scenarios of a fuel cell lifetime.
\end{abstract}

\section{INTRODUCTION}

Recently published report on world's energy status highlighted that despite record amounts of energy was generated from renewable sources, fossil fuel consumption was also record high in 2015 (BP plc 2016). As a result, global $\mathrm{CO}_{2}$ emissions continued to increase, what is unacceptable if the targets of Paris Agreement ever to be reached (UNFCCC 2015). Therefore it is essential to develop efficient and sustainable power generation technologies that will help to shift the global energy landscape away from fossil fuels.

One of leading ways for fossil fuel consumption is transportation. Hence reducing dependency of transport on carbohydrates is essential. Electric vehicles (EVs) are the prime candidates for the future of automotive industry. Among different types of EVs, fuel cell-powered vehicles (FCV) have the potential to form the future of energy consumption.

\subsection{PEM Fuel cell technology}

Fuel cells are a class of power generation devices that use hydrogen fuel to produce electrical power. The output power is the result of direct transformation of chemical energy stored within fuel by an electrochemical process. There are different types of FCs, but in this work polymer electrolyte membrane (PEM) fuel cells are investigated. At the heart of a PEMFC is the polymer membrane, primary function of which is to conduct protons from the anode to the cathode. At either side of the membrane are catalyst layers that facilitate the chemical reactions. Next to the catalyst are the gas diffusion layers (GDLs) which deliver the reactants to the reaction sites evenly through the diffusion process. The combination of the membrane, catalyst and GDLs forms a single component called the membrane electrode assembly (MEA). The MEA is sandwiched between two bipolar plates, which provide structural backbone to the fuel cell, and supply reactant gases via the gas flow channels embedded in them. The overall structure of PEMFC is shown in Figure 1.

During the fuel cell operation, the hydrogen gas is supplied at the anode electrode. Hydrogen diffuses through the GDL to the anode catalyst layer where the oxidation reaction (Eq. 1) releases the electrons $\left(e^{-}\right)$ and hydrogen ions $\left(H^{+}\right)$.

$2 \mathrm{H}_{2} \rightarrow 4 \mathrm{H}^{+}+4 e^{-}$

The released electrons flow to the cathode electrode through an external circuit, thus generating useful work. At the same time, the protons move to the cathode through the membrane. The oxygen (whether as air or pure) supplied to the cathode facilitates the reduction reaction (Eq. 2) in which electrons and protons are consumed to create water molecules $\left(\mathrm{H}_{2} \mathrm{O}\right)$ and generate some by-product heat.

$\mathrm{O}_{2}+4 \mathrm{H}^{+}+4 e^{-} \rightarrow 2 \mathrm{H}_{2} \mathrm{O}+$ heat 


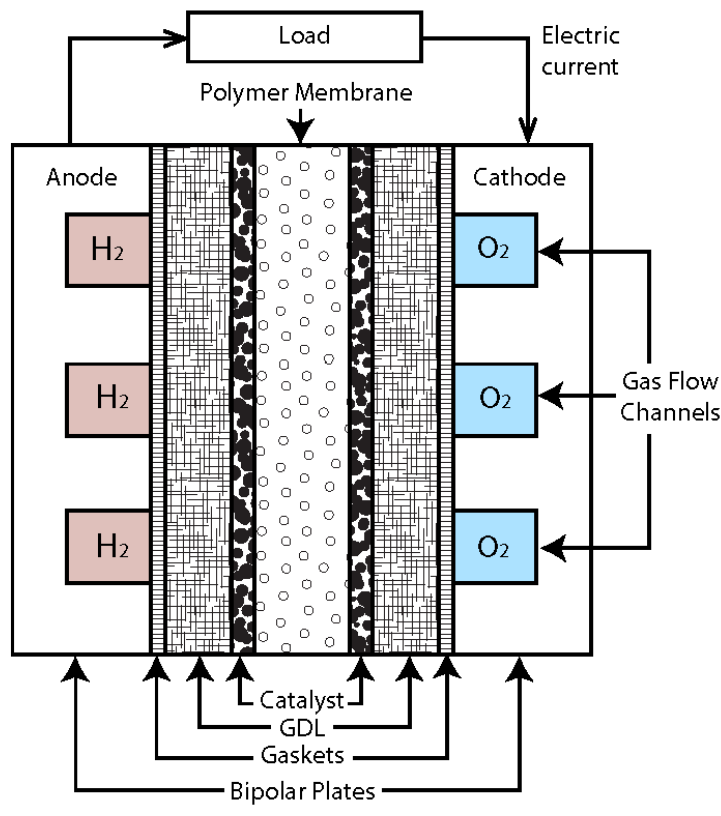

Figure 1. Structure of a PEM fuel cell.

Equations 1 and 2 show that the only by-products of the fuel cell operation are water vapor and heat, what is advantageous compared to conventional internal combustion engines.

\subsection{Balance of plant components}

A single PEMFC generates about $1 \mathrm{~V}$, so in order to produce higher voltages, multiple cells are connected in series to create a fuel cell stack.

Additional components and sub-systems are required to create the necessary conditions for efficient FC stack operation.

Hydrogen fuel is usually stored in compressed tanks, while air is delivered to the stack from the atmosphere by fans or compressors.

The reactant supply sub-systems consist of pipes, valves, mass flow controllers, pressure regulators and filters. Temperature regulation is achieved by either circulating liquid coolant (e.g. water) or air fans or blowers. Gas humidification equipment is also important in order to maintain appropriate levels of water content within the membrane.

All the balance of plant components aim to maintain the stack at constant temperature, pressure and humidification with minimized disturbance. Any deviations from a set operating point will lead to decreased performance and increased rates of degradation.

\subsection{PEM Fuel Cell Reliability Issues}

Current generation of PEM fuel cells faces a number of issues that limit their lifetime performance. The reliability of the total PEM fuel cell system is determined by the durability of each individual component. For example, membrane degradation affects its ion and water transport properties, catalyst layer deterioration causes the decrease of chemical reaction activity, while aging of the gas diffusion layer hinders the supply of reactants to the reaction sites. In addition to the aging process, variations in the operating conditions imposed by the auxiliary equipment may accelerate or decelerate the degradation effects. For example, failures in the cooling subsystem may create high temperatures (i.e. above $80{ }^{\circ} \mathrm{C}$ ) what boosts the reaction kinetics, but, simultaneously, increases the rate of catalyst degradation. On the other hand, low temperatures facilitate conditions for liquid water accumulation in the gas supply channels and the membrane, what leads to flooding of gas supply channels, causing the drop in voltage output. Faults in the reactant supply sub-systems creates reactant starvation, what leads to the creation of local hotspots and further membrane disintegration.

In other words, PEM fuel cell durability is governed not only by natural aging processes, which cannot be averted, but also by the operating conditions imposed on it by the environment and the supporting equipment (Wang et al. 2011). Therefore, reliability of the PEM fuel cell component is directly linked to the reliability of the auxiliary equipment and it is crucial to design the system such that the influence of auxiliary equipment failures on the fuel cell stack is minimized. Reliability assessment of PEM fuel cells is important in order to provide estimations for expected lifetime predictions of the system and advise on possible hardware optimizations.

\section{LITERATURE REVIEW}

Publications on reliability analysis of PEM fuel cell systems mostly utilized classical techniques such as failure mode and effect analysis (FMEA) and fault tree analysis (FTA).

A report by the US Department of Transportation contains an FMEA table for the balance of plant of a fuel cell-powered vehicle (Stephens et al. 2009). The report discusses three aspects of the vehicle - compressed hydrogen fuel storage, hydrogen flow control, and the fuel cell stack. According to the analysis, the failures associated with the fuel cell stack sub-system are more likely to occur and bear high degree of criticality and risk. Within the fuel cell itself, authors identified the mechanical failure of the membrane to be the most critical failure mode.

Other authors developed FMEAs with the focus on fuel cell components and materials. Authors of (Wang et al. 2011) performed an in-depth analysis of the causes and consequences of fuel cell materials degradation. While publication by (Rama et al. 2008) provides the analysis from phenomenological point of view by focusing on various events that lead to the performance deterioration.

Paper by (Placca \& Kouta 2011) describes fault trees for the three main components of a fuel cell - membrane, catalyst layer and the GDL. The authors also 
compile a list of failure rates for each basic event in the fault tree in order to estimate the probability of occurrence of top events quantitatively.

FTA performed by (Yousfi Steiner et al. 2011) was aimed at the water management issues of PEMFCs. The authors developed fault trees of membrane flooding and drying-out. The changes of the system state variables, such as temperature, relative humidity and stack current, were defined as basic events.

In (Brik et al. 2015) also construct a fault tree for the fuel cell system degradation with sub-trees that include system auxiliary components, membrane degradation and electrode degradation. The authors determined minimal cut sets, but provided no quantitative results due to the lack of reliability data. Another fault tree analysis carried out by (Whiteley, Dunnett, et al. 2015) shows that the Boolean logic of fault trees is not ideal method for estimating the probability of fuel cell failure due to complex dependencies of failure modes on the operating conditions. Authors highlight that a different FT needs to be constructed for all possible operating conditions, what is not realistic.

A different technique applied to reliability analysis of PEMFCs is Petri net modelling. Authors of (Wieland et al. 2009) created a simple Petri net for stack degradation, and maintenance. However, the model does not consider the different failure modes of the system components and simply includes only 'working' and 'failed' states. Spontaneous and repair events affect the lifetime voltage variation, while failure rates are assumed constant.

Degradation modelling by means of Petri nets was carried out by (Whiteley, Fly, et al. 2015). The authors designed 21 Petri net sub-modules corresponding to various degradation phenomena such as radical attack and start-up/shut-down cycles.

Paper by (Fecarotti et al. 2016) presented an extended Petri net modelling approach for representation of auxiliary components together with the fuel cell stack. Monte Carlo simulations provided estimation of expected lifetime of the system under certain operating conditions and maintenance schedule.

All of the aforementioned techniques are limited by the assumption of failure rates which do not depend on changing operating states of the system, thus overestimating the system performance.

In order to account for such dependencies, a more detailed modelling approach is needed. An approach that is capable of handling both constantly evolving state variables as well as randomly occurring events. Such approach to reliability assessment is an emerging field of study called 'dynamic reliability'. Even though dynamic reliability has the potential to offer greater accuracy, it has not found a widespread adoption within industry and only a narrow group of researchers are investigating this field (Labeau et al. 2000; Marseguerra et al. 1998). In recent years, sub- stantially increased computing power allowed researchers to implement principles of dynamic reliability in computer simulations. For example (Ferdinando Chiacchio et al. 2016; F. Chiacchio et al. 2016; Manno et al. 2013) created a stochastic hybrid automaton model of a cooling system for a data center in Matlab/Simulink environment. The authors showed how temperature variations due to environmental and local effects alters the failure rate of the system. Another approach to dynamic reliability was demonstrated in (Codetta-Raiteri \& Bobbio 2005) by employing an extension of generalized hybrid petri nets (GSPN) called fluid stochastic Petri nets (FSPN). In this paper, the differential equations governing the continuous-time evolution of the system were coded directly into the Petri net. This, however, requires the Petri net code to be written for specific modelling purposes and cannot be reused in different scenario.

Based on the conducted literature review two conclusions can be drawn. Firstly, reliability modelling and assessment of PEM fuel cells is still in early stages of development. Secondly, dynamic reliability is an emerging field of study and new tools that allow straightforward implementation of such models are needed. In this paper, we propose a novel model for dynamic reliability of PEMFCs based on the combination of two inter-dependent bond graph and Petri net models. The modelling technique is also a contribution to the field of dynamic reliability.

\section{MODELLING METHOD}

The modelling approach proposed in this paper attempts to rectify the limitations of classical reliability modelling techniques by considering physical behavior of the system together with possible events occurring during system lifetime. In order to do this, two types of sub-models - deterministic and stochastic are developed and linked together to create an overall hybrid model. In this section, the deterministic submodel is investigated first, followed by the stochastic one.

\subsection{Deterministic model}

The model is developed with the bond graph approach and is the extension of the model previously presented at ESREL 2015 (Vasilyev et al. 2015). It contains the differential equations that describe continuous time dynamics of state variables such as pressure, temperature and mass flows. Time-evolution of these variables dictates the power output of the fuel cell system. Some of the most important equations are provided here, but more information can be found in (O’Hayre et al. 2006). 


\subsubsection{Voltage output}

The maximum electrical potential of an ideal fuel cell at open circuit and given temperature and pressure is determined by the Nernst equation:

$E_{\text {Nernst }}=-\frac{\Delta G}{2 F}+\frac{R T}{2 F} \ln \left(\frac{p_{H_{2}} \sqrt{p_{O_{2}}}}{p_{\mathrm{H}_{2} \mathrm{O}}}\right)$

where $\Delta G$ is the change of Gibbs free energy, $\mathrm{F}$ is the Faraday constant $(96,485 \mathrm{C} / \mathrm{mol}), R$ is the ideal gas constant, $T$ is the temperature $(\mathrm{K}), \alpha$ is the transfer coefficient, $p_{\mathrm{H}_{2}}, p_{\mathrm{O}_{2}}, p_{\mathrm{H}_{2} \mathrm{O}}$ are partial pressures of hydrogen, oxygen and water vapour $(\mathrm{Pa})$.

However, as soon as the electrical load is applied to the cell, different voltage loss mechanisms begin to occur. As a result the output voltage is expressed by the following equation:

$V_{f c}=E_{\text {Nernst }}-\eta_{\text {act }}-\eta_{\text {ohm }}-\eta_{\text {con }}$

where terms $\eta_{a c t}, \eta_{o h m}, \eta_{c o n}$ describe the voltage loss phenomena.

Activation losses $\eta_{\text {act }}$ represent the amount of energy consumed to overcome the activation barrier and sustain the electrochemical reaction:

$\eta_{a c t}=\frac{R T}{2 \alpha F} \ln \left(\frac{i}{i_{0}}\right)$

where $i$ is the current density $(\mathrm{A} / \mathrm{cm} 2)$ and $i_{0}$ is the exchange current density $(\mathrm{A} / \mathrm{cm} 2), \alpha$ is the transfer coefficient.

Ohmic losses $\eta_{\text {ohm }}$ result from the fuel cell material's internal resistance to the transport of charged particles (electrons and ions), i.e. ohmic $R_{o h m}$ and ionic $R_{\text {ion }}$ resistances:

$\eta_{\text {ohm }}=I_{f c}\left(R_{o h m}+R_{\text {ion }}\right)$

where $I_{f c}$ is the current load (A). It is important to note that $R_{i o n}$ is a strong function of water content $\sigma$ within the membrane. When $\sigma$ is low, $R_{\text {ion }}$ is high and vice versa. Hence it is important to maintain appropriate levels of membrane humidification in order to minimise the ohmic losses.

Concentration losses $\eta_{\text {con }}$ occur when the reactant gases are consumed faster than they are supplied to the reaction sites.

$\eta_{\text {con }}=\frac{R T}{2 \alpha F} \ln \left(\frac{i_{L}}{i_{L}-i}\right)$

where $i_{L}$ is the limiting current density $\left(\mathrm{A} / \mathrm{cm}^{2}\right)$ which is determined by the reactant concentration at the reaction sites.

\subsubsection{Pressure dynamics}

The ideal gas law determines changes in reactant pressure within the volume of gas supply channels:

$\frac{M_{\text {gas } V}}{R T}\left(\frac{d P}{d t}\right)=\sum_{\text {in } / o u t} \dot{m}_{\text {gas }}$

where $\mathrm{P}$ is the total pressure of the gases in the gas flow channels, $\mathrm{V}$ is the volume of the channels, $m_{\text {gas }}$ is the total mass of gases.

\subsubsection{Thermal dynamics}

The temperature of the fuel cell changes according to the following energy balance equation:

$c_{p} m_{f c} \frac{d T}{d t}=\dot{Q}_{f c}-\dot{Q}_{c o o l} \pm \dot{Q}_{a m b}+\dot{H}_{\text {in }}-\dot{H}_{o u t}$

where $c_{p}$ is the specific heat capacity of the fuel cell, $m$ is the mass of the cell, $T$ is the temperature, $\dot{Q}_{f c}$ is the amount of heat generated by the reaction, $\dot{Q}_{c o o l}$ is the amount of thermal energy exchanged with the coolant, $\dot{Q}_{a m b}$ is the heat loss to the environment. $\dot{H}_{\text {in }}$ and $\dot{H}_{\text {out }}$ are the enthalpies of the gases carried in and out of the fuel cell stack calculated as follows:

$\dot{H}_{\text {in } / \text { out }}=c_{\text {p,gas }} \dot{m}_{\text {gas }} T_{\text {gas }}$

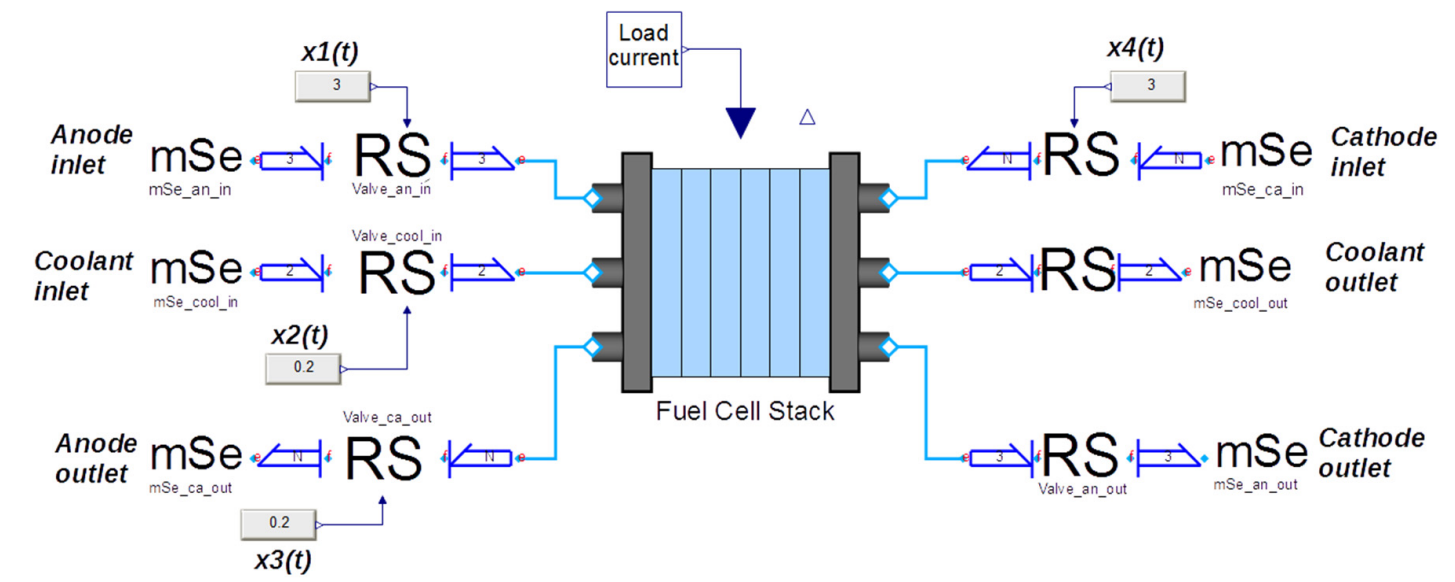

Figure 2. Fuel cell stack model implemented with BondLib and MultiBondLib libraries 


\subsubsection{Degradation modelling}

Modelling the degradation behaviour of a PEM fuel cell is a complex task due to the lack of understanding of the internal processes and complex nature of the phenomena. In this work, several time-dependent laws for fuel cell degradation, first proposed in (Jouin et al. 2015), are used. The increase of leak current density is expressed via an exponential relation as:

$i_{\text {leak }}(t)=i_{\text {leak }, 0} \exp \left(b_{\text {leak }} t\right)$

where $i_{\text {leak }, 0}$ is the estimated initial leak current density, $b_{\text {leak }}$ is a degradation parameter. The increase of ionic resistance is modelled as:

$R_{\text {ion }}(t)=R_{\text {ion, } 0} \exp \left(b_{\text {ion }} t\right)$

where $R_{i o n, 0}$ is the initial ionic resistance and $b_{i o n}$ is the degradation parameter. The deterioration of the GDL diffusivity is characterised as:

$D_{O_{2}}(t)=D_{O_{2}, 0}+b_{D} t$

where $D_{O_{2}, 0}$ is the initial diffusivity of oxygen through the GDL, and $b_{D}$ is the parameter describing the rate of loss of diffusivity.

\subsection{Stochastic model}

The second part of the hybrid model operates in discrete-time domain. It is implemented with stochastic Petri nets and is capable of representing various system states and events occurring during fuel cell lifetime.

\subsubsection{Petri nets}

Petri nets are a graphical and mathematical modelling tool for representation of variety of systems and processes. Petri net is a bipartite graph consisting of two types of nodes - places and transitions. A collection of places represents the set of possible system states. Transitions between the places correspond to various events that occur during the system lifetime. The state of the system at any point in time is characterised by Petri net marking. A place marked with an integer $k$ is said to contain $k$ tokens. The change of system state is governed by transition firing when certain conditions are met. When a transition fires it removes tokens from all the input places and puts a token into all output places. Once all conditions are met, transitions firing can occur at random or predetermined intervals of time. Graphically, places are represented by circles and transitions are drawn as rectangles.

\subsection{Hybrid Model Implementation}

It is desirable to have a unified programming environment for representation of the hybrid models. Simulink was utilised for this purpose in (F. Chiacchio et al. 2016) and Modelica (Modelica Association 2016) in (Bouissou et al. 2014). Since the fuel cell submodel described by Equations 3-13 was initially implemented using Modelica, this language was chosen for development of current model.

Modelica is an object-oriented modelling language for physics-based modelling of engineering systems. Multiple additional libraries that extend the basic set of Modelica tools can be installed or created. As such, BondLib (Cellier \& Nebot 2005) and MultiBondLib (Zimmer \& Cellier 2006) libraries designed specifically for bond graph modelling were used in creation of the fuel cell model. Figure 2 depicts the fuel cell sub-model. Elements labelled ' $m$ Se' determine the pressures of gases and liquids entering and leaving the stack. While 'RS'-elements controlled by external signal blocks labelled ' $\mathrm{x} 1(\mathrm{t})$ '-' $\mathrm{x} 4(\mathrm{t})$ ' regulate the mass flow rates.

Another library called PNlib (Proß \& Bachmann 2012) was applied for modelling the stochastic petri net sub-model. The library contains the code and graphical representation for all essential Petri net elements. There are two types of places - discrete and continuous, three types of transitions - discrete, stochastic and continuous. Figure 3 illustrates the icons of all the PNlib elements used in this paper.
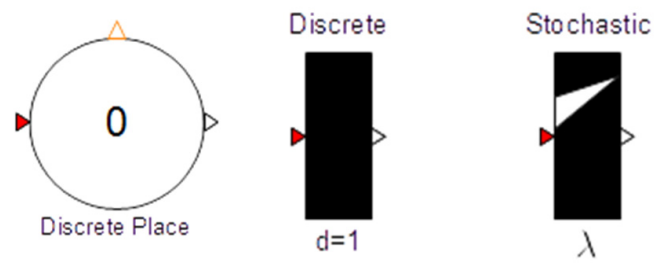

Figure 3. Petri net elements in PNlib

Discrete place can only hold an integer number of tokens, while discrete transition fire at deterministic intervals of time, determined by parameter $d$. Stochastic transition, on the other hand, fires at random intervals of time, by sampling from an exponential (or Weibull) distribution described by the following function:

$f(t)=\lambda e^{-\lambda t}$

where $\lambda$ is the hazard rate. Each transition can have additional firing condition dependant on some external variable.

Petri nets in Modelica are created by simply dragging and dropping the required elements on to the editor window and connecting them with arcs. Assigning weights, setting firing conditions and initialising the state of the places can be done through the 'Parameters' dialog window. 
Each place has connectors that output the number of marks located in it. Therefore, combining the two sub-models as easy as connecting the output connectors of needed Petri net places to the input connectors of the deterministic model.

\subsubsection{Demonstration Example}

In this example, the fuel cell sub-model is configured in such a way that a valve regulates the coolant flow rate. The state of health of the valve is described by one working state and four states for each possible failure mode:

- Valve blocking

- Internal passing

- External leak

- Fail to operate

A Petri net as shown in Figure 4 represents the state of health of the valve.

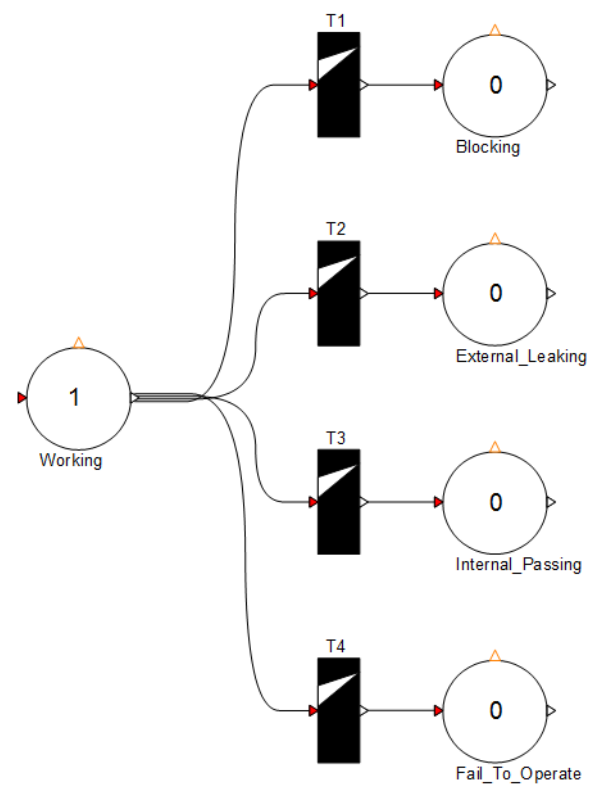

Figure 4. Petri net of valve states of health

In Figure 4 place 'Working' on the left-hand side corresponds to a healthy valve operating as expected. Stochastic transitions T1-T4 have hazard rates set to 20 failures per million hours (Smith 2005). Places to the fight-hand side represent the four associated failure modes of the device.

Additionally, the valve has four states of operation:

- Open

- Closed

- Partially open

- Partially closed

Figure 5 illustrates the PN for the corresponding operational states of the valve. Deterministic transitions in Figure 5 are instantaneous (0 firing delay time), but depend on the temperature of the fuel cell according to the following rules:

1. Transitions T5, T6, T7 and T8 can fire only when the temperature of the fuel cell is lower than some predefined threshold.

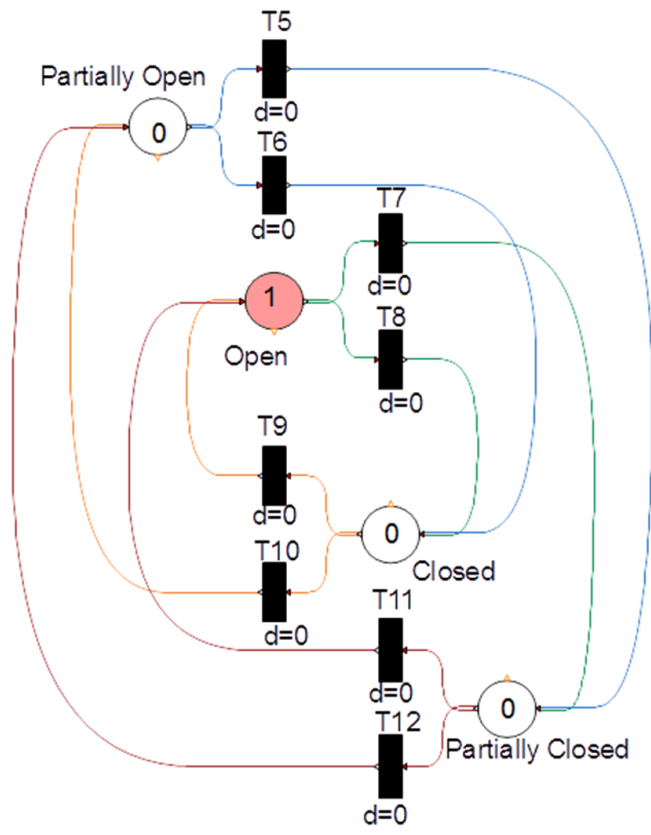

Figure 5. Operational states of the valve

2. Transitions T9, T10, T11, and T12 can fire when the temperature exceeds the threshold.

The two PNs in Figures 4 and 5 are connected such that when the valve is working as intended (i.e. place 'Working' contains a token), the token jumps between places 'Open' and 'Closed'. Whenever either 'Blocking' or 'Internal Passing' are marked, the operational behaviour of the valve is changed. Therefore, the token now takes a different path either 'Open' to 'Partially Closed' or 'Partially Open' to 'Closed'.

The values of tokens in places of Figure 5 control the value of control signal $x_{2}(t)$ (see Figure 2) that regulates the mass flow rate of the coolant. So when the valve is fully open, $x_{2}(t)=1$, when it is closed, $x_{2}(t)=0$.

\section{SIMULATIONS \& RESULTS}

In order to perform Monte Carlo simulations, the stochastic transitions need a new seed for the random number generator. The seed can be automatically generated by a built-in Modelica block 'GlobalSeed' from within the 'Noise' toolbox. The hybrid model is augmented with this block and compiled as an executable file by an open-source OpenModelica (Open Source Modelica Consortium 2016) compiler. Running the executable file produces an .xml file that contains all the initial conditions of the model and a .mat file that contains the results of the simulation. A MatLab script then performs a set number of simulations, extracts the necessary data from the result file and performs data processing for reliability analysis. In this work, 1000 simulations of 5000 hours of system lifetime were performed. The end of fuel cell life- 
time was assumed to be when a $10 \%$ loss of performance occurred with no voltage recovery over a cumulative period of 100 hours.

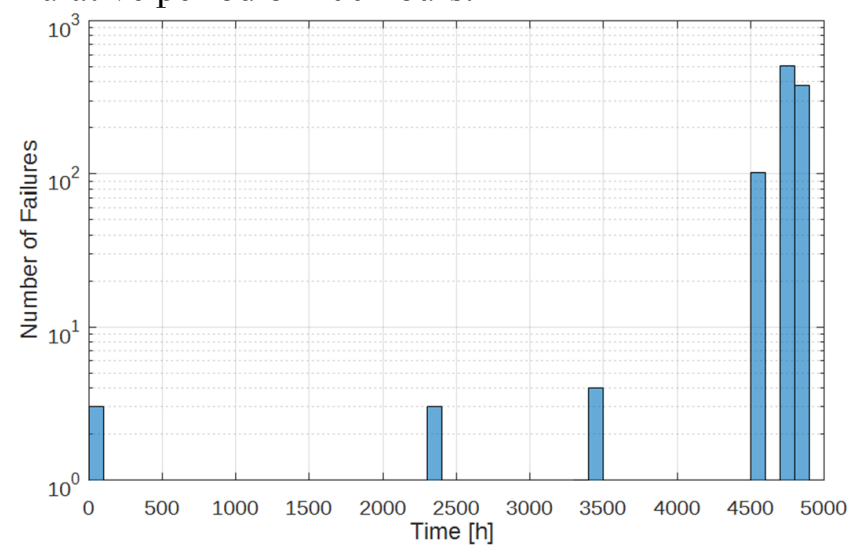

Figure 6. Distribution of system lifetime over 5000 hours.

Simulation results shown in Figure 6 show that the probability of system survival for at least 4500 hours is high. Several failures of the cooling system occurred early in its lifetime (peaks at 0, 2400 and 3500 hours) which caused overheating of the fuel cell stack. However, the majority of fuel cell breakdowns occurred at the end of system lifecycle (from 45005000 hours) due to ageing. In this simulation, failures of only one auxiliary component were considered, so inclusion of failure modes for all other components will yield results that are more realistic.

\section{CONCLUSIONS AND FUTURE WORK}

In this paper, a novel modelling approach for reliability assessment of PEM fuel cells was presented. The approach expands the continuous-time deterministic dynamics of the system with discrete-time stochastic behavior.

The analysis of PEM fuel cell operating principles and degradation phenomena served as a starting point for this research. Additionally, the literature review revealed that there is a need to perform a comprehensive reliability analysis of PEM fuel cells with consideration of operating states of the system.

The hybrid modelling approach makes use of stochastic Petri nets to model the different failure modes of system auxiliary components. The behavior of the Petri net depends on the fuel cell state variable, while changes of Petri net state affect the fuel cell dynamics. Monte Carlo simulations performed using a MatLab script generated a distribution of best and worst life-times of the system.

In addition to that, the Modelica modelling language showed it's flexibility and applicability to modelling and simulation of dynamic reliability problems.

Current model will be expanded with additional failure modes and enhanced degradation modelling in order to provide a more in-depth reliability assessment of PEM fuel cell systems.

\section{ACKNOWLEDGEMENTS}

The authors gratefully acknowledge the support of EPSRC (grant number EP/K02101X/1) which has enabled the research reported in this paper.

\section{REFERENCES}

Bouissou, M. et al., 2014. Efficient Monte Carlo Simulation of Stochastic Hybrid Systems. In 10th International Modelica Conference. Lund, Sweden, pp. 715-725. Available at: http://www.ep.liu.se/ecp_article/index.en.aspx?issue=96; article $=75$.

BP plc, 2016. BP Statistical Review of World Energy, Available at: $\quad \mathrm{http} / /$ www.bp.com/content/dam/bp/pdf/energyeconomics/statistical-review-2016/bp-statistical-reviewof-world-energy-2016-full-report.pdf.

Brik, K. et al., 2015. Causal and Fault Trees Analysis of Proton Exchange Membrane Fuel Cell Degradation. Journal of Fuel Cell Science and Technology, 12(5), p.51002. Available at: http://fuelcellscience.asmedigitalcollection.asme.org/artic le.aspx?doi=10.1115/1.4031584.

Cellier, F.E. \& Nebot, A., 2005. The Modelica Bond Graph Library.

Chiacchio, F. et al., 2016. SHyFTA, a Stochastic Hybrid Fault Tree Automaton for the modelling and simulation of dynamic reliability problems. Expert Systems with Applications, 47, pp.42-57. Available at: http://dx.doi.org/10.1016/j.eswa.2015.10.046.

Chiacchio, F. et al., 2016. Stochastic hybrid automaton model of a multi-state system with aging: Reliability assessment and design consequences. Reliability Engineering \& System Safety, 149, pp.1-13.

Codetta-Raiteri, D. \& Bobbio, A., 2005. Evaluation of a benchmark on dynamic reliability via Fluid Stochastic Petri Nets. In Proceedings of the 7th international workshop on performability modeling of computer and communication systems. pp. 52--55.

Fecarotti, C., Andrews, J. \& Chen, R., 2016. A Petri net approach for performance modelling of polymer electrolyte membrane fuel cell systems. International Journal of Hydrogen Energy, 41(28), pp.12242-12260.

Jouin, M. et al., 2015. PEMFC aging modeling for prognostics and health assessment. IFAC-PapersOnLine, 48(21), pp.790-795. Available at: http://www.sciencedirect.com/science/article/pii/S24058 96315017528 [Accessed October 20, 2015].

Labeau, P.E., Smidts, C. \& Swaminathan, S., 2000. Dynamic reliability: towards an integrated platform for probabilistic risk assessment. Reliability Engineering \& System Safety, 68(3), pp.219-254.

Manno, G. et al., 2013. Dynamic reliability analysis of three nonlinear aging components with different failure modes characteristics. In Safety, Reliability and Risk Analysis: Beyond the Horizon. pp. 3047-3055.

Marseguerra, M. et al., 1998. A concept paper on dynamic reliability via Monte Carlo simulation. Mathematics and Computers in Simulation, 47, pp.371-382.

Modelica Association, 2016. Modelica. Available at: https://modelica.org/ [Accessed October 11, 2016]. 
O’Hayre, R. et al., 2006. Fuel Cell Fundamentals, John Wiley $\&$ Sons.

Open Source Modelica Consortium, 2016. OpenModelica. Available at: www.openmodelica.org [Accessed October 11, 2016].

Placca, L. \& Kouta, R., 2011. Fault tree analysis for PEM fuel cell degradation process modelling. International Journal of Hydrogen Energy, 36(19), pp.12393-12405. Available at: http://www.sciencedirect.com/science/article/pii/S03603 19911015655 [Accessed February 5, 2016].

Proß, S. \& Bachmann, B., 2012. PNlib - An Advanced Petri Net Library for Hybrid Process Modeling. Proceedings 9th Modelica Conference, Munich, Germany, pp.47-56.

Rama, P., Chen, R. \& Andrews, J., 2008. A review of performance degradation and failure modes for hydrogenfuelled polymer electrolyte fuel cells. Proceedings of the Institution of Mechanical Engineers, Part A: Journal of Power and Energy, 222(5), pp.421-441. Available at: http://pia.sagepub.com/lookup/doi/10.1243/09576509JPE 603 [Accessed November 5, 2013].

Smith, D.J., 2005. Reliability, Maintainability and Risk Seventh Ed., Elsevier.

Stephens, D.R. et al., 2009. Failure Modes and Effects Analysis for Hydrogen Fuel Cell Vehicles, Columbus, $\mathrm{OH}$.

UNFCCC, 2015. Paris Agreement,

Vasilyev, A., Dunnett, S.J. \& Jackson, L.M., 2015. ModelBased Fault Detection and Isolation of PEM fuel cells using Bond Graphs. In Safety and Reliability of Complex Engineered Systems - Proceedings of the 25th European Safety and Reliability Conference, ESREL 2015.

Wang, H., Li, H. \& Yuan, X.-Z., 2011. PEM Fuel Cell Failure Mode Analysis, CRC Press.

Whiteley, M., Fly, A., et al., 2015. Advanced reliability analysis of Polymer Electrolyte Membrane Fuel Cells using PetriNet analysis and fuel cell modelling techniques. International Journal of Hydrogen Energy, 40(35), pp.11550-11558. Available at: http://www.sciencedirect.com/science/article/pii/S03603 19915002463 [Accessed February 25, 2016].

Whiteley, M., Dunnett, S. \& Jackson, L., 2015. Failure Mode and Effect Analysis, and Fault Tree Analysis of Polymer Electrolyte Membrane Fuel Cells. International Journal of Hydrogen Energy, 41(2), pp.1187-1202. Available at: http://www.sciencedirect.com/science/article/pii/S03603 19915303694 [Accessed January 2, 2016].

Wieland, C. et al., 2009. Reliability computing of polymerelectrolyte-membrane fuel cell stacks through Petri nets. Journal of Power Sources, 190(1), pp.34-39. Available at: http://www.sciencedirect.com/science/article/pii/S03787 75308019009 [Accessed February 25, 2016].

Yousfi Steiner, N. et al., 2011. Application of Fault Tree Analysis to Fuel Cell diagnosis. Fuel Cells.

Zimmer, D. \& Cellier, F., 2006. The Modelica Multi-Bond Graph Library. Modelica Conference, pp.559-568. 